\title{
EDUCAÇÃO INFANTIL, GÊNERO E MORALIDADE: UMA PROPOSTA DE FORMAÇÃO HUMANA
}

Hildineia Alves

Antonio Francisco Marques

RESUMO: A Educação Infantil, por meio da Lei de Diretrizes e Bases, visa ao desenvolvimento integral da criança de zero a cinco anos em seus aspectos físico, afetivo, cognitivo e social. Nesta fase as crianças aprendem conteúdos pedagógicos de modo lúdico, experenciam o convívio e o respeito ao próximo sem estranhamentos, sejam eles sexistas, racistas ou qualquer diferença que, infelizmente, a sociedade traduz como preconceito. No presente trabalho, busca-se mostrar um recorte da pesquisa de Mestrado sobre moralidade e gênero na Educação Infantil. O objetivo é apresentar um dos resultados obtidos acerca do que as crianças pensam sobre o juízo moral e as questões de gênero. A metodologia teve um caráter qualitativo e a técnica utilizada foi o grupo focal. As respostas das crianças possibilitam compreender o quanto suas falas são desprovidas de preconceitos, aprendidos socialmente. Esse espaço da Educação Infantil revela-se como um terreno fértil para construção de uma formação mais humana, autônoma e menos sexista.

PALAVRAS-CHAVE: Educação Infantil. Gênero. Moralidade. Formação Humana

\section{INTRODUÇÃo}

A Educação Infantil na contemporaneidade, dentro de um processo longo, vai se firmando como uma prática educativa fundamental na formação humana da infância nas sociedades contemporâneas. Se ainda, nas condições concretas de muitas sociedades, não se tem a clareza do que esta prática social representa para a formação das novas gerações, pelo menos no imaginário social ela toma uma dimensão utópica do que a educação traz para os indivíduos e para as sociedades, no seu processo civilizacional.

Esse reconhecimento político-social se dá como resultado da afirmação da criança como sujeito da educação, sobretudo por influência de movimentos intelectuais como o Renascimento e Iluminismo. Reforçado no século XIX, com surgimento e progresso das ciências sociais e pela consolidação das instituições educativas burguesas

Que puseram cada vez mais no centro da pedagogia a criança, assumida na sua especificidade psicológica e na sua função social. A infância foi vista como uma idade radicalmente diferente em relação à vida adulta, submetida a um processo evolutivo complexo e conflituoso, emotivo e cognitivo, portadora, porém, de valores próprios e exemplares: da fantasia à igualdade, à comunicação. Assim, a criança tornou-se o sujeito educativo por excelência, reclamando uma rearticulação das instituições educativas, reclamando o "jardim de infância" ao lado da escola, porque é justamente na idade pré-escolar que se desenvolve o germe da personalidade humana (CAMBI, 1999, p. 387).

No Brasil houve muitos avanços quanto à garantia do acesso das crianças à Educação Infantil por parte da sociedade e do Estado brasileiro. Nas últimas décadas, com a sua afirmação, como direito legal, que veio direcionar políticas públicas com vistas ao seu atendimento. A Educação Infantil passa a fazer parte da educação básica. O reconhecimento destes níveis do sistema educacional como básico " é um conceito mais do que inovador para um país que por séculos negou, de modo elitista e seletivo, a seus cidadãos o direito ao conhecimento pela ação sistemática da organização escolar". (CURY, 2008, p.70).

Entretanto, a lei em si não muda a realidade, trata-se de um processo histórico e social das gerações passadas e presente, que está em curso para as gerações futuras. Dentro desse movimento de devir, há avanços e recuos, com conflitos e negações, " as escolas infantis no Brasil 
sofreram, no decorrer dos tempos, diferentes mudanças em suas funções, as quais passaram pelo assistencialismo, custódia e privação cultural até a função educativa" (PASCOAL e MACHADO, 2009, p.58).

Há posturas críticas nos meios educacionais de que, no presente, há um recuo ou mesmo nunca houve um avanço efetivo na garantia dos direitos humanos básicos de parcela significativa da população brasileira, secularmente oprimida com a negação de sua humanidade. Miguel Arroyo, no ano passado, ao recordar os 50 anos da publicação da obra de Paulo Freire, a Pedagogia do Oprimido, vê novos tempos de opressão, que recoloca a necessidade de uma "nova radicalização ético-política ao pensamento pedagógico, à educação". Trata-se de interrogações postas por "sujeitos" no mundo sendo-não-sendo no mundo, na economia, na política, na educação (ARROYO, 2019, p. 2).

Documentos oficiais do próprio governo federal, apontaram em 2002, a denegação histórica desses direitos para a infância. Por mais que não se possam negar avanços para superação dessa realidade, ela continua, de modo gritante, no momento presente.

As crianças brasileiras, em especial as crianças pequenas, de zero a seis anos, filhas de famílias pobres, vivem uma situação que mostra um grande distanciamento entre os direitos assegurados nos textos legais e suas condições reais de vida (BRASIL, 2002).

\section{Educação e HUMANização}

Postas estas primeiras considerações sobre a Educação Infantil, o que nos interessa aqui é focar numa perspectiva de qual educação nos interessa para a garantir às crianças o seu direito à humanização. Num contexto reconhecido de que estes novos sujeitos que chegam aos espaços da escola pública vêm de um mundo onde lhes são negados os direitos mais elementares de seres humanos.

O desafio posto está em democratizar a educação básica para todos os grupos sociais no contexto de uma sociedade classista e desigual. Portanto, não é qualquer escola quando se pensa nestes grupos sociais que antes não tinham acesso à escola da infância ou, quando tinham, estava marcada pelo mero assistencialismo. A superação dessas políticas se faz por investimento público para criação de espaços físicos adequados para o atendimento destes educandos e pela formação do quadro pedagógico profissional para estas entidades escolares. Anteriormente, onde havia atendimento para essa faixa etária predominava a improvisação de profissionais leigos para o atendimento das crianças. Passa ainda por criação de currículos que atendam às demandas de formação humana dos educandos. Para que isso aconteça é fundamental levarem em conta a diversidade dos alunos a serem atendidos. A diversidade a ser tomada como projeto cultural e educativo " enquadrado em um determinado contexto, e entre as características desse projeto necessariamente devem figurar a participação e a autonomia” (IMBERNÓN, 2000, p.87).

Os avanços apontados passam pelo fato de que ela é agora compreendida como uma etapa obrigatória e com direitos de aprendizagem desde a Educação Infantil. Essa etapa educacional vem, aos poucos, conseguindo se desvincular do seu embrião assistencialista e higienista.

A Constituição Federal de 1988 (BRASIL, 1988) já retratava a educação de crianças de 0 a 5 anos em creches, pré-escolas e instituições similares como direito do cidadão e dever do Estado. Ao ser tratada em lei a Educação Infantil começa a ser de fato pensada como um direito 
e não apenas como assistência ou auxílio, acrescido da responsabilização do Estado para sua oferta.

Além disso, a CF/88 (BRASIL, 1988) em seu artigo 6 "São direitos sociais a educação, a saúde, o trabalho, o lazer, a segurança, a previdência social, a proteção à maternidade e à infância, a assistência aos desamparados, na forma da lei ". Vale refletir sobre qual infância a CF está se referindo, haja vista que no Brasil podemos pensar em "Infâncias".

As infâncias são construídas socialmente e são influenciadas pelas questões sociais onde estão inseridas como classe social, raça/cor, gênero e sexualidade. Ademais, o termo "criança", no Referencial Curricular Nacional para a Educação Infantil, documento que orienta a prática dos(as) professores(as), desta etapa educacional, também explicita que "[...] concepção de criança é uma noção historicamente construída e consequentemente vem mudando ao longo dos tempos, não se apresentando de forma homogênea nem mesmo no interior de uma mesma sociedade e época" (BRASIL, 1998, p. 21). A justificativa está no fato de que antes da modernidade essa etapa da vida não era reconhecida como um estágio específico no processo de desenvolvimento da criança, o reconhecimento da adolescência é algo mais tardio.

A CF/88 (BRASIL, 1988), em seu artigo $4^{\circ}$, inciso IV, além de assegurar a educação escolar a crianças de zero a seis anos de idade, que atualmente compreende até os cinco anos; estendeu a garantia da gratuidade, que antes não era mencionada, para creches e pré-escolas, possibilitando a oportunidade de atendimento educativo público e gratuito a todos que assim o desejarem.

O direito à Educação foi renovado pelo Estatuto da Criança e do Adolescente (ECA) - Lei n8.069/1990 (BRASIL, 1996) e pela Lei de Diretrizes e Bases da Educação Nacional (LDBEN) (BRASIL, 1996), que passou a integrar a Educação Infantil, juntamente com o Ensino Fundamental e o Ensino Médio. Perante tais documentos a Educação Infantil passa a ser reconhecida como primeira etapa da Educação Básica no Brasil.

Com a promulgação do ECA - Lei n8.069/1990 (BRASIL, 1990), os municípios se tornaram responsáveis pelos direitos da criança e do adolescente com o apoio e criação de Conselho e fundos Municipais, além do Conselho Tutelar. Em seu artigo $2^{\circ}$ Lei nº.069/1990 (BRASIL, 1996) estabelece a delimitação entre criança e adolescente, a faixa etária da criança é de zero a doze anos e adolescente o de doze a dezoito anos de idade. Argumenta-se que essa determinação entre criança e adolescente passa a ver a criança como um ser em desenvolvimento psicológico, social e cultural pois:

Existem limitações que são objetivamente determinadas pela idade: uma criança não está apta para exercer certas atividades próprias de adultos, da mesma forma que um velho já não é capaz de realizar algumas tarefas. Estes impedimentos decorrem geralmente da incapacidade do desempenho de funções que dependem da força física ou agilidade, como as referentes à guerra, à caça etc. Entre outras funções podemos incluir as que dependem do acúmulo de uma experiência obtida através de muitos anos de preparação. Torna-se fácil entender por que estas são interditadas às crianças e aos jovens e reservadas às pessoas maduras, como certos cargos políticos etc. (LARAIA, 2004, p.81)

O direito à Educação Infantil também é explicitado na Lei n¹2.796, de 4 de abril de 2013 (BRASIL, 2013), que altera a Lei $\mathrm{n}^{\circ} 9.394$, de 20 de dezembro (BRASIL, 1996), estabelecendo 
as Diretrizes e Bases da Educação Nacional, para dispor sobre a formação dos(as) profissionais da educação e dar outras providências, dispõe em seu artigo 29:

A educação infantil, primeira etapa da educação básica, tem como finalidade o desenvolvimento integral da criança até cinco anos, em seus aspectos físico, psicológico, intelectual e social, complementando a ação da família e da comunidade (BRASIL, 1996).

A Lei 12.796, de 4 de abril de 2013, lei que estabelece as diretrizes e bases da educação nacional, foi sancionada pela então presidente Dilma Rousseff, dessa vez garantindo o direito da criança à Educação Infantil. Em seu artigo $6^{\circ}$ a lei prevê que "[...] é dever dos pais ou responsáveis efetuar a matrícula das crianças na Educação básica a partir dos quatro anos de idade" (BRASIL, 2013).

A CF/88 (BRASIL, 1988) não garantiu a Educação Infantil como uma etapa educacional obrigatória, tendo em vista que era um dever do Estado sua oferta e uma escolha dos pais garanti-la aos seus filhos e filhas. Somente com a Lei 12.796 (BRASIL, 2013), que estabelece as Diretrizes e Bases da Educação Nacional, dispõe em seu artigo $5^{\circ}$ :

O acesso à educação básica obrigatória é direito público subjetivo, podendo qualquer cidadão, grupo de cidadãos, associação comunitária, organização sindical, entidade de classe ou outra legalmente constituída e, ainda, o Ministério Público, acionar o poder público para exigi-lo. (BRASIL, 2013).

Desse modo, apenas a partir de 2013 a Educação Infantil foi reconhecida como etapa educacional obrigatória e como efetiva responsabilidade da família.

Assim, a Educação Infantil apresenta-se como direito e dever, sendo pois um direito da criança ao estudo e um dever do Estado e dos pais. Ambos vão garantir as condições necessárias para que a criança possa usufruir de seu direito em sua condição de ser em desenvolvimento. Já os educadores auxiliam os pais para uma formação mais humana e autônoma.

\section{Formação humANA, DESENVOLVimento MORAL E IGUALDADE DE GÊNERo}

Uma formação mais humana e autônoma do indivíduo envolve como os valores e as regras sociais são transmitidas pela educação que o sujeito recebe nos diversos espaços sociais e nas instituições educacionais em que vive. Essas experiências sociais e educacionais é que vão mediar relação do indivíduo com a cultura onde nasce e vive. Nos espaços não formais de aprendizagem boa parte da bagagem cultural adquirida pelo indivíduo se dá de modo acrítico e passivo. Os espaços formais de educação representado pela escola têm como objetivo "provocar e facilitar a reconstrução dos conhecimentos, atitudes e formas de conduta que os alunos/as assimilam direta e acriticamente nas práticas sociais de sua vida anterior e paralela à escola" (GÓMEZ, 2007, p. 25).

A sociedade para se manter precisa formar seus membros, com um conjunto de habilidades, crenças e valores compartilhados por todos. Ela realiza esse processo por meio da educação, que se dá tanto nos espaços não-formais como nos formais. Isto não significa a homogeneização dos indivíduos, mas sim o respeito pela heterogeneidade social e pela individuação dos educandos. De acordo com Sacristán (2000) isso leva a

manter e estimular, a partir das primeiras experiências de materiais herdados, a liberdade, a independência pessoal, o valor da expressão de cada um e da autonomia dos sujeitos como sementes das quais poderá nascer uma atitude crítica para a reconstrução 
da tradição em etapas avançadas da escolarização. Uma liberdade que não nega nem se opõe ao esforço, mas que dele necessita (SACRISTÁN, 2000, p. 51).

Ao pensar uma sociedade democrática, que supere todos os mecanismos de domínio e opressão - de indivíduos, grupos sociais, povos e nações - é imprescindível uma educação igualitária e libertadora, que como já pontuamos neste trabalho, está longe de acontecer. Sendo possível perceber que almejamos uma educação pautada no pilares da democracia e do respeito à diversidade, mas ainda não conseguimos atingi-la. E um de nossos desafios como educadores tem sido "como produzir uma educação libertadora e humana, que promova verdadeiramente a autonomia de todos os sujeitos a altura dos ideais iluministas da modernidade?" E para tanto temos que refletir se realmente estamos pensando em uma formação efetivamente humana em nosso meio social.

O contexto brasileiro é marcado por uma hierarquia social e classista, cuja polarização não se reflete apenas no âmbito governamental. Também na família, na escola, no trabalho e no cotidiano de maneira geral, percebe-se uma tradição de relações sociais autoritárias. Nesse contexto, o aparato legal acaba se tornando um instrumental privado, estranho, portanto, à perspectiva de uma autêntica arena pública, horizontal e radicalmente democrática. (STRECK et al, 2014, p.125)

Diante dessa representação de distanciamento da sociedade brasileira dos pilares de uma cultura democrática, se impõe pensar uma escola infantil, no caso deste estudo, que busque em seu processo formativo a criação de uma nova sociabilidade. Para atingir esse objetivo a formação moral das crianças tem um papel imprescindível. Por isso, nosso recorte, neste estudo, tem como foco central o desenvolvimento moral e as relações de gênero.

Se as práticas sociais, na escola ou em outras entidades, mudam, nem sempre transformam no sentido libertador ou igualitário. No contexto sociedade das sociedades contemporâneas - de modo específico a brasileira que é foco deste estudo - a promoção da igualdade de gênero é fundamental para a conquista da cidadania pelos indivíduos.

A educação para a cidadania é um processo que decorre ao longo da vida. Começa em casa e/ou no meio próximo das crianças com as questões que vão surgindo na vida quotidiana a propósito das relações interpessoais, da identidade, das escolhas, da justiça, do bem e do mal e vai-se desenvolvendo à medida que se expandem os horizontes de vida. A promoção de uma maior igualdade de gênero é um elemento fundamental na educação para a cidadania e na construção de uma verdadeira democracia. Lidar com as diferenças sem as transformar em desigualdades é um dos grandes desafios da educação na atualidade. (CARDONA et al, 2015, p. 59)

Pensar no desenvolvimento da moralidade como uma prática cotidiana de respeito ao próximo e nas relações de gênero pautadas no respeito mútuo "[...] além de um substituto para o termo mulheres, é também utilizado para sugerir que qualquer informação sobre as mulheres é necessariamente informação sobre os homens, que um implica o estudo do outro". (SCOTT, 1995, p.75). Analogamente, estudar gênero implica considerar que tais relações são permeadas por questões morais, no sentido dos educandos alcançarem no seu processo formativo, que se estende por toda a vida, a maioridade. Isto é, sujeito do próprio destino, apesar dos determinantes do contexto onde vive e se desenvolve. 
Para Piaget (1994) uma educação autoritária e coercitiva pode afirmar relações unilaterais, reforçar o realismo moral na criança e produzir sujeitos heterônimos. Esse autor nos remete a pensar sobre a possibilidade de relações entre iguais, relações de reciprocidade, que podem alcançar a verdadeira autonomia de meninas e meninos sem distinções de gênero. Desse modo, as relações de meninas e meninos são um fenômeno de ordem social e cultural que podem ser transformadas e a educação desempenha importante papel nesse processo de transformação. (LOURO, 1997, p.28).

Pensar em relações de reciprocidade e de gênero na educação e, de modo específico no cotidiano escolar, para Pelúcio (2015) implica desconstruir e redescobrir significados. Significa organizar a prática educacional, possibilitando que as crianças experimentem a autonomia e conheçam infinitos tipos de papéis, sem determinar posições e comportamentos para meninas e meninos, oportunizando a todas e todos relações sociais mais humanas e menos sexistas.

A pesquisa aqui apresentada neste artigo é parte de um estudo que teve como objetivo identificar as concepções das crianças sobre gênero e moralidade, de modo a reconstruir a realidade de uma escola de Educação Infantil por meio da oralidade dos sujeitos que dela participam e a modificam (ALVES, 2020). A perspectiva teórica da pesquisa é piagetiana ao tratar do desenvolvimento moral da criança.

As ideias de Yves de La Taille (2005) serão o fio condutor para fundamentar essas proposições acima levantadas. Proposições relacionadas a valores priorizados pela nossa sociedade, valores que se iniciam desde nosso nascimento, mas que se fortalecem por volta dos 4 anos, idade em que a criança começa a compreender o universo das regras morais (LA TAILLE, 2005; PIAGET, 1994). Desse modo, podemos inferir quão relevante é o trabalho dos educadores da Educação Infantil na construção dos valores humanizadores, haja vista que tais valores começam a ser fortemente assimilados justamente nessa faixa etária.

Num primeiro momento vale esclarecer o significado que pretende-se utilizar em relação à palavra valor como um investimento afetivo (LA TAILLE, 2005). À medida que um objeto (no sentido de objeto de conhecimento, uma pessoa, um grupo, uma ideia, objeto físico) torna-se um valor para uma pessoa, se nela despertar algum valor afetivo, ou seja, que não a deixe indiferente.

Pautando-nos nessa definição, fica evidente perceber que a criança adquire valores desde que nasce, haja vista que muito possivelmente remete sua afetividade nos mais diversos objetos de conhecimento ao seu redor. Embora, segundo Piaget (1994), na fase sensório motora (de 0 a 2 anos), a criança não tenha consciência dessa aquisição de valores, quando passa a fazer uso da linguagem ela já consegue verbalizar o que gosta ou o que não gosta.

No entanto, o universo das possibilidades dos valores é ampliado por novos objetos de conhecimento que são inseridos no contexto social da criança. Entretanto, se por volta dos 2 anos a criança ainda não tem a consciência da aquisição de valores, em que idade ela começa a adentrar esse universo moral?

Ocorre por volta dos 4 anos, conforme citado anteriormente, sendo que antigamente, e por vezes ainda hoje, acreditava-se que as condutas das crianças pequenas eram pautadas pelo medo de punições e pelo desejo de recompensas, sem desfrutar de nenhuma sofisticação intelectual para compreender a moral ou mesmo sem investimentos afetivos que traduzem valores morais. Atualmente, segundo La Taille (2005), é de conhecimento que no universo da criança pequena 
há noções de moralidade, ainda que de modo rudimentar, que vão desenvolver-se, aprimorar-se com o tempo, mas que também merecem importância, principalmente em âmbito educacional.

Nesse sentido, La Taille (2005) explica que a partir dos 4 anos a criança começa a perceber que existem coisas que se fazem e outras coisas que não devem ser feitas. $\mathrm{O}$ caráter de obrigatoriedade, característico da moral, distingue-se do simples hábito pertinente às demais rotinas e demais condutas.

Para tanto, a definição limita-se ao rol dos valores morais, referente às regras de conduta consideradas obrigatórias, sendo pois, da ordem do dever. Nesse sentido, segundo La Taille (2005), uma pessoa terá um comportamento moral apenas se reconhecer intimamente seus deveres e pautada neles fundamentar suas condutas. Reconhecer intimamente seus deveres não tem relação com o comportamento realizado por medo de castigo ou por expectativas de recompensas, pois se assim for, a conduta não será considerada moral, pois a determinação do desprazer ou do prazer não estabelece a disciplina interior e a consciência moral.

La Taille (2005) define a relação entre moral e valores. Afirmando a necessidade de explicitar melhor o que é uma regra, após a compreensão da regra com seus princípios, fica mais evidente a relação destes com os valores morais.

Uma regra pode ser definida como um postulado verbal que nos direciona com precisão ao que devemos ou não fazer. Agir moralmente seria, então conformar-se às regras da moral. Exemplos como esses ocorrem diariamente nas escolas, repletos por regras que por muitas vezes não são construídas ou elaboradas com as crianças e sim impostas pelos adultos. Desse modo, as regras são feitas pelos adultos, os quais por meio de sua autoridade, ou seja, representante de sua sociedade, transmitem as regras às crianças.

Puig (2019) em sua entrevista concedida (ARANTES; ARAUJO; SILVA, 2019) explica que não basta aos professores terem conhecimentos teóricos sobre como compreender a educação em valores, para ele é necessário saber transformar a teoria em práticas e propostas formativas para serem aplicadas em instituições escolares.

Ao ser questionado sobre sua trajetória no campo de estudos da moralidade e o contexto em que ela foi realizada, Puig (2019) enfatiza sua opinião explicando:

O trabalho de pesquisa e aplicação prática que levamos a cabo, seja qual for sua qualidade, teria sido completamente impossível se não tivesse sido feito coletivamente. Ele enriqueceu-nos e permitiu-nos enfrentar tarefas que ninguém poderia ter feito sozinho. Eu acho que isso é o mais relevante. (ARANTES; ARAUJO; SILVA, 2019, p. 6).

E como as crianças aprendem as regras da sociedade em que vivem? Por meio da teoria ou por meio de situações práticas? Como, por exemplo, não matar, não roubar, falar a verdade. Sabemos que as crianças aprendem os deveres e as regras morais por meio de uma educação moral, transmitida pelos pais, mestres, parceiros, muito mais por modelos apresentados do que por discursos, estes muitas vezes apresentados de maneira moralizante. Mais do que isso, esses processos de transmissão de valores morais levam, na maioria das vezes, à limitação de formação da criança "apenas nos valores do próprio grupo social, que continuamente se veem ameaçados pela convivência de outros grupos" (BARREIRO, 2014, p. 197).

Assim, a superação desses limites para formação de instância moral da vida cidadã

a ênfase se passa pela transmissão de valores ao desenvolvimento de pensamento envolvido nas questões morais, com a finalidade de formar sujeitos autônomos, capazes 
de julgar as situações compreendendo as diferentes perspectivas envolvidas, ou seja, capazes de compreender os interesses e sentimentos dos outros e confrontá-los em um processo argumentativo (BARREIRO, 2014, p. 197).

Embora o primeiro contato com a moral ocorra com a criança, por meio de regras, no âmbito educacional, não exime o professor de explicar às crianças a razão de ser dessas regras. Justamente em uma relação de diálogo é possível uma educação mais humanizada e democrática.

Essas regras fazem parte de nossa constituição, enquanto seres sociais para que possamos discernir o que é bom do que é mau. Porém, sempre com a figura de uma autoridade, sendo na escola a presença do educador. Esse educador deve ter a vontade, a autoridade e o sentimento da própria autoridade. Sendo que essa vontade e autoridade vêm da função do professor de formar os indivíduos para a sociedade. A autoridade do professor pode ser análoga ao sacerdote como uma "missão". Sobretudo, será que essa pressão educativa dos professores ou dos pais é a única maneira de transmitir regras e valores? Essa é a única forma de conduzir as crianças para a educação moral? Para ser livre a criança precisa que alguém a conduza?

A criança não sabe diferenciar sociabilidade e a individualidade, ela está centrada no ponto de vista dela mesma, esta é a fase que Piaget (1994) denomina de egocentrismo infantil. Para que a criança saia desse nível é necessário um desenvolvimento, e para tal, a relação de reciprocidade se põe como facilitadora. Já a relação de autoridade freia e barra o desenvolvimento inteligente e autônomo do sujeito. Como, por exemplo, a educação bancária, criticada por Paulo Freire (1996), os conteúdos escolares prontos são depositados na mente dos educandos que os recebe de forma passiva e sem nenhuma negociação de significados dos conteúdos apresentados com os conhecimentos prévios dos educandos que trazem de suas experiências na escola e fora dela.

Piaget (1994) explica que para Durkhein autoridade e liberdade são correlatos, donde a liberdade é a autoridade bem compreendida. Já Piaget questiona essa relação, indaga se poderemos ser livres nos submetendo sempre à autoridade. Questiona se é possível uma verdadeira autonomia moral. E indaga também se a única relação é de um superior sobre um inferior? Como pensarmos em uma educação humanizadora com práticas autoritárias?

Questionamentos também levantados pelos estudos das relações sociais de gênero que não aceitam um dominador e um dominado, um homem mandando em uma mulher, acreditando, assim como Piaget, em outras possibilidades de relações sociais.

Para Durkheim autônomo é aquele que conhece as regras e leis morais e se submete à autoridade, pela regra unilateral, já para Piaget existe autonomia parcial, pois, segundo ele, como ser autônomo e me submeter a uma regra que considero injusta? Uma reflexão justamente da regra da reciprocidade.

La Taille (1992, p.17) escreve sobre os diversos graus de socialização postulados por Jean Piaget e ele define que "[...] autonomia significa ser capaz de se situar consciente e competentemente na rede dos diversos pontos de vista e conflitos presentes numa sociedade". Vale acrescentar que Autonomia moral para Piaget considera o sujeito e leva em conta os interesses bem como as regras do grupo. Esse sujeito que coopera tem mais individualidade, pois sabe o ponto de vista próprio e dos outros. O que favorece a formação desse indivíduo autônomo e mais humanizado é a relação de reciprocidade. 


\section{O PERCURSO METODOLÓGICO E UMA INTERVENÇÃo HUMANIZADORA}

Ao pensar em uma formação mais humanizadora e promotora da autonomia, desenvolveu-se este trabalho qualitativo interpretativo. De modo a reconstruir a realidade de uma escola de Educação Infantil por meio da oralidade dos sujeitos que dela participam e a modificam. A técnica de coleta de dados utilizada foi o grupo focal (GATTI, 2005). O procedimento é pautado na realização de atividades em grupo. Elas foram realizadas com 22 alunos, com a idade de 5 anos, de uma escola de educação infantil.

As 22 crianças foram divididas em quatro grupos, da seguinte forma: dois grupos com cinco crianças, sendo um grupo de meninas e outro de meninos e dois grupos com seis crianças sendo um com duas meninas e quatro meninos e o outro com três meninas e três meninos. "Nessas escolhas, o conhecimento e julgamento do pesquisador é que irão balizar a composição do grupo", relacionando o objetivo da pesquisa com algum traço em comum entre os participantes, ou seja, as questões de gênero, para identificar as concepções de meninas e meninos sobre moralidade e gênero visando promover momentos de reflexão dentro de um processo de educação para uma educação mais humana e emancipadora. (GATTI, 2005, p. 19).

Com a intenção de corroborar com o método de coleta de dados sem medição numérica, optou-se pela técnica de pesquisa do grupo focal (GATTI, 2005). A técnica aplicada em grupos abarca atividade coletiva, sendo recomendado que os participantes tenham alguma vivência com o tema a ser discutido. Técnica empregada com o intuito de captar conceitos, sentimentos, experiências pessoais, valorização da fala infantil, além da captação de significados "de um modo que não seria possível com outros métodos, como, por exemplo, a observação, a entrevista ou questionários". (GATTI, 2005, p.9).

Apesar de amplamente utilizada com adultos, a técnica de grupo focal é pouco explorada em pesquisa com crianças e menos ainda com crianças tão pequenas, sendo ínfimas as referências literárias que abordam o assunto. A pesquisadora acredita que se essa técnica permite captar conceitos, sentimentos e experiências pessoais, ela é a técnica mais adequada para a valorização da fala infantil de modo espontâneo, haja vista que quando observamos as crianças ou realizamos entrevistas com elas, as mesmas apresentam-se um pouco tímidas ou receosas. Ao passo que o grupo focal permite a interação entre os participantes, as crianças têm a possibilidade de falar mais livremente sobre os temas propostos em cada grupo baseados em suas vivências.

Pensando nessa vivência com o tema a ser discutido, por crianças tão pequenas, elaboraram-se histórias que ocorrem e/ou podem ocorrer no cotidiano escolar, histórias que envolvem crianças brincando no pátio da escola, histórias que utilizam o nome de animais para identificar o que as crianças entendem e pensam sobre questões morais e sobre diferenças de gênero.

Bernadete Gatti (2005) alerta para alguns cuidados metodológicos como o respeito para com o princípio da diretividade, e certa formação do facilitador em trabalhos com grupos. Para tanto, a facilitadora (pessoa que facilita o processo de conversa entre os membros do grupo) foi a própria pesquisadora, a qual já trabalhou e trabalha com grupos em sua prática profissional e elaborou um roteiro de discussões semiestruturado com vistas a uma intervenção que possibilitasse a troca, a partilha de ideias, a multiplicidade de pontos de vista e não intervenções afirmativas ou negativas. Garantindo assim, trocas efetivas e possibilidades de identificar como essas crianças pensam e por que pensam o que pensam. 
Para compreender a construção da realidade da escola onde foi realizada a pesquisa deste grupo de crianças em específico, utilizou-se o procedimento com quatro grupos focais, indicado por Gatti, para uma mesma investigação a fim de orientar a proposta de intervenção por meio de uma sequência didática de atividade pedagógica.

Além da facilitadora/pesquisadora, houve a participação de uma anotadora (que registrou os encontros em vídeos, fotos e áudios). Vale ressaltar que a facilitadora e a anotadora foram as mesmas durante os 11 encontros dos grupos focais.

A pesquisa foi realizada com apenas uma sala de aula porque no ano de 2019, ano de realização da mesma, houve apenas duas classes de Etapa II, ou seja, de crianças de cinco anos, sendo uma no período da manhã e outra no período da tarde. Como a pesquisadora precisou do período oposto ao seu horário de trabalho para realizar a pesquisa, a mesma só pôde ser aplicada com uma sala de aula, sendo a do período da tarde.

Gatti (2005) recomenda que os participantes não tenham informações detalhadas sobre o objeto de pesquisa. Considerando essa informação, para cada grupo foi apresentada uma história por dia, de modo que cada grupo tivesse acesso às quatro histórias, mas as mesmas foram alternadas durante os dias dos encontros, para que o contato entre as crianças na sala de aula não possibilitasse o conhecimento sobre as discussões, garantindo assim que não houvesse interferência nas participações das crianças de grupo para outro.

A escolha pelos grupos focais fora feita com o objetivo principal de desenvolver e fundamentar uma técnica, detalhada por Gatti (2005) que permite a escuta de crianças pequenas em uma pesquisa de caráter qualitativo, por meio de um método de compreensão de dados subjetivos, sobre suas experiências e vivências infantis e que nesta pesquisa singular, se propôs a identificar as concepções sobre gênero e moralidade, pela fala das próprias crianças, visando a promover uma reflexão dentro de um processo de Educação mais humana e emancipatória.

\section{Resultado e discussão}

A pesquisadora elaborou algumas histórias que ocorrem ou podem ocorrer em um cotidiano escolar, neste trabalho, em especial, apresentaremos apenas uma das histórias, com o título de "Tartaruga".

Várias crianças estavam no pátio brincando de correr, estavam brincando de apostar corrida, corriam da parede até o portão. Mas uma das crianças sempre chegava em último lugar, todas as vezes que corria. As crianças começaram a chamá-la de "Tartaruga".

O objetivo com essa história era desvendar a concepção das crianças sobre possíveis situações de preconceito, analisando o que elas entendem e pensam sobre os diferentes tipos de personalidade e se relacionam essas personalidades ao gênero. Após ler a história a seguinte pergunta foi feita às crianças nos 4 grupos: Quem pode me explicar o que aconteceu?

As crianças dos quatro grupos demonstraram compreender a história lida pela pesquisadora, pois explicaram, cada uma ao seu modo o que aconteceu. Ficou nítido na fala de Ferreira (G1): "Ela é lenta", que chamar pelo nome de tartaruga tem relação com a personalidade da criança em ser "rápida ou lenta". Há uma justificativa para a lentidão quando Fernanda fala que ela "...tava muito cansada" e Clarice e Cora (G2) falam que "...andou de bicicleta e caiu”. 
As crianças que estão ouvindo uma das histórias pela primeira vez (G1 e G2) ainda não retratam sentimentos na primeira pergunta. Já as crianças do G3 e G4, que já ouviram outras histórias da pesquisa, relatam sentimentos pelos acontecimentos logo na primeira pergunta, como é o caso de Lygia (G3): "Eles ficam muito triste" e Fernando (G4): "Eles ficaram triste"

Em relação a possíveis soluções para os acontecimentos as crianças que já ouviram alguma história também trazem esse tipo de relato logo na primeira pergunta. Na fala de Lygia (G3): "Daí eles vão pra diretora. Fica de castigo lá na casa e na escola. E no projeto". Eva também fala: "Vai na diretora" Para Carlos (G4): "Em nenhum lugar pode chamar, nem no pátio, nem em casa nem na escola".

Perante a pergunta por que vocês acham que as crianças chamavam-na de "tartaruga"?

Novamente as falas infantis retratam que a criança da história era "devagar", ao passo que quando Clarice (G2) diz: "Porque eu acho que ela anda muito rápido, eu ando rápido". Imediatamente, Ana: (Falou olhando para Clarice e apontando com o dedo indicador) - "Não é rápido, tá andando devagar". Desse modo, a riqueza do grupo focal incide justamente em possibilitar que as crianças interajam entre si, onde o mediador apenas oferece condições para tal interação. (Gatti, 2005). Situação evidenciada também na fala de Eva (G3): "Já falô!".

Já Rebeca (G4) expressa sentimento em sua fala ao dizer: "Porque não gostava dela". O que nos permite pensar que para essa criança de modo particular, xingar um amigo está diretamente relacionado ao sentimento de amizade que se tem por ela e não a personalidade da criança de ser "lenta ou rápida".

Para entender como as crianças pensavam no uso da palavra tartaruga, para se referir a outra criança, realizou a pergunta: O que é tartaruga?

As crianças dos quatro grupos referem-se à tartaruga apenas como um animal, explicam que ela é lenta, fazem movimentos com as mãos para demonstração, retratam que ela tem um casco. Por fim as crianças usam a imaginação e a fantasia ao dizerem: Eva: "E eles correm das pessoas"; Chico: "E da abelha e tudo"; Augusto Boal: "E da bruxa" (G3). Criam uma história para o animalzinho; Ruth: "Tartaruga... ela vive lá na praia"; Mário: "E na floresta" (G4).

É provável que o Augusto tenha pensado que a tartaruga é um animal lento porque é nova de idade. Pois ele já tem 5 anos e não usou a idade dele, disse uma idade menor que a dele.

Ao partilharem conhecimentos, ficam evidentes os estudos de Piaget sobre a aprendizagem das crianças com os iguais, desprovidas de preconceitos sexistas. Essa modalidade de Educação compartilhada advém dos ensinamentos do grande educador brasileiro Paulo Freire que escreve: "Quem ensina aprende ao ensinar e quem aprende ensina ao aprender. Quem ensina, ensina alguma coisa a alguém" (FREIRE, 1996, p. 12).

Essa proposta de aprendizagem coletiva, sem disputas de quem sabe mais ou menos, e sem distinções de gênero foram evidenciadas em várias situações e em todos os grupos. As crianças da Educação Infantil dialogaram entre si, perguntaram, falaram e relataram suas experiências sem reforçar situações de preconceito.

A fim de entender como as crianças pensam sobre moralidade e as relações de gênero, a pesquisadora elaborou histórias evolvendo o cotidiano escolar e elaborou algumas perguntas às crianças. Para a pergunta: A criança que foi chamada de tartaruga era menino ou menina? Por quê? 


\begin{tabular}{|l|c|c|}
\hline \multicolumn{1}{|c|}{ GRUPOS } & TARTARUGA É MENINA & TARTARUGA É MENINO \\
\hline G1 MENINOS & 2 & 2 \\
\hline G2 MENINAS & 4 & 1 \\
\hline G3 MISTO & 1 & 1 \\
\hline G4 MISTO & 3 & 8 \\
\hline TOTAL & 10 & \\
\hline \multicolumn{2}{|c|}{ Quadro de análise elaborado pela pesquisadora } \\
\hline
\end{tabular}

Nesta pesquisa pudemos perceber que as crianças não relacionam a personalidade de ser lerdo a uma questão de gênero, ao passo que lançam outras hipóteses para explicar porque acham que é menina ou menino.

Podemos inferir que Ferreira (G1) acredita que a criança que era chamada de tartaruga era uma menina, que usa saia, e que esta vestimenta pode limitar seus movimentos no momento de correr. Nelson (G1) relata que "menino corre pouco".

As crianças do G1, por exemplo, percebem que o "termo" tartaruga foi empregado para representar uma criança que é devagar e lenta. Entretanto não atribuem a lentidão a uma discriminação conforme o gênero. Haja vista que 2 crianças acharam que era menina e 2 acharam que era menino. Embora seja uma amostra pequena, 50\% dos meninos afirmaram que a criança lenta era um menino. Para esse grupo de crianças ser lenta não estabelece relação com o fato de ser menina ou menino, as crianças demonstram ser características distintas e independentes. Infelizmente, muitos adultos atribuem a lentidão a mulher, por considerá-la como a possuidora do "sexo frágil" e delicado, como se ela não pudesse ser ágil porque nasceu mulher.

Para as crianças "tartaruga" é uma palavra feminina e por isso parece óbvio que a criança que assim foi chamada é, portanto, uma menina.

Para entender como as crianças pensam sobre os sentimentos de uma criança que sofre preconceito, foi realizada a pergunta: Como essa criança se sentiu?

Em todos os grupos o nome do sentimento que apareceu foi "triste", Augusto Boal (G3) fala: "Porque não pode, daí ela ficou chorando". Pelas falas infantis é possível deduzir que as crianças compreendem que qualquer amigo fica triste ao ser xingado, já entendem que xingar não é um comportamento adequado em nossa sociedade.

E para entendermos como as crianças pensam sobre solucionar problemas, em como pensam em serem mais colaborativas umas com as outras, foi realizada a seguinte pergunta: $\mathrm{O}$ que podemos fazer nesta situação?

As falas das crianças perante essa pergunta sobre resolução de conflitos nos fazem refleti, o quanto nós, adultos, não estimulamos as crianças a resolverem seus problemas e conflitos, apenas ensinamos que se acontece alguma coisa ela deve falar para um adulto. O que, de certo modo, faz a criança pensar que ela própria é incapaz de pensar em soluções, precisando sempre de um adulto para intermediar.

Por outro lado, podemos refletir sobre o quanto precisamos oportunizar outros espaços de diálogos, como o dessa pesquisa, para possibilitarmos uma educação mais humana e menos preconceituosa, na prática cotidiana e não apenas na teoria acadêmica.

Pensar, então, em uma educação que envolva múltiplas linguagens, com o envolvimento e a entrega que envolve a experiência compartilhada entre todas(os) as(os) que estão nas instituições de educação infantil, adultas(os) e crianças, implica refletir sobre as ex- 
periências formativas que efetivamente toquem e transformem as(os) profissionais que atuam com as(os) pequenas(os). Cursos, palestras, oficinas, reuniões e tantas outras atividades propostas para a formação inicial e continuada das(os) professoras(es) têm priorizado a informação em detrimento da experiência que transforma e que é, literalmente, incorporada às práticas educativas cotidianas com as crianças. (PRADO; ALSELMO, n.p. 2019)

A ausência de espaços para compartilhar conhecimentos e para promover a autonomia permite que a heteronomia continue a se fazer presente, como na fala de Cora, a qual acredita que a medida a ser tomada é castigar a criança que chamou a outra de tartaruga (PIAGET, 1994). Essa afirmação confirma ainda mais o pensamento de Cora, porque se a mãe dela colocou sua irmã de castigo, esse comportamento punitivo the parece adequado para a criança que apresenta um comportamento inadequado socialmente.

Quantas vezes nós incentivamos a criança a comer para crescer. Por vezes, sem perceber, não consideramos o estágio de desenvolvimento em que ela se encontra como um período bom. Fazemos do momento presente da criança um período preparatório para a fase adulta. Como se apenas a fase adulta fosse de fato importante, ignorando sobremaneira as atividades infantis como etapas necessárias para um bom desenvolvimento do ser humano. E essa criança teve a sensibilidade de perceber e falar que não gosta de ser adulto, que prefere ser criança porque criança brinca.

\section{Conclusões}

Perante a análise dos resultados podemos inferir que almejamos uma escola pautada nos pilares democráticos, desejamos uma escola que de fato contemple a formação integral da criança, conforme previsto na Legislação. Porém, ainda falta compreensão e formação docente para a oferta de uma educação que promova a autonomia de modo mais humanizado.

No cotidiano dessa escola, a coação e as relações unilaterais continuam porque o adulto não se refez, apenas reproduz atos. Entendemos, segundo Piaget (1994) e conforme as falas infantis, que uma possibilidade de transformação desta prática está no aprendizado de relações de cooperação, reciprocidade e respeito mútuo entre meninas e meninos sem diferenciação de gênero. Para que isto aconteça

há que assumir as potencialidades das crianças enquanto aprendizas, reabilitando a vi-
são da criança enquanto intérprete, interlocutora e autora do processo educativo (enten-
dido também como processo comunicativo) e aceitar que as crianças pequenas também
aprendem coisas complexas, podendo chegar a universos adultos de reflexão e conheci-
mento, desde que os meios de comunicação (e motivação!) sejam adequados e devida-
mente planificados (CARDONA, 2015, p. 62).

Em nossa sociedade, bem como nas escolas, há diferenças significativas nas formas como a masculinidade e a feminilidade são representadas por relações unilaterais e de superioridade. Esse tipo de relação pode dificultar o desenvolvimento autônomo de algumas crianças. Pois, conforme pudemos observar com a história da tartaruga, as crianças não relacionam a lentidão do animal a nenhum ser humano e também não distinguem o ser lento ao menino ou à menina.

No entanto, na Educação Infantil as crianças ainda não sabem diferenciar sociabilidade e individualidade, pois estão centradas em seu próprio ponto de vista, ao que Piaget (1994) denomina egocentrismo. 
Para que a criança supere esse nível é necessário estabelecer relações de reciprocidade entre adultos/ crianças e meninas/ meninos. Oferecer às crianças espaços e oportunidades de refletir e dialogar sobre relações mais igualitárias, com práticas pedagógicas que viabilizem o respeito mútuo, a cooperação e o desenvolvimento do juízo moral autônomo de modo mais humanizado desde a Educação Infantil.

\section{CHILDHOOD EDUCATION, GENDER AND MORALITY: A PROPOSAL FOR HUMAN TRAINING}

ABSTRACT: Early childhood education, through the Law of Guidelines and Bases, aims at the integral development of children from zero to five years in its physical, affective, cognitive and social aspects. In this phase, children learn pedagogical content in a playful way, experience socializing and respect for others without strangers, be they sexist, racist or any difference that, unfortunately, society translates as prejudice. In this paper, we seek to show an excerpt of the Master's research on morality and gender in Early Childhood Education. The goal is to present one of the results obtained about what children think about moral judgment and gender issues. The methodology had a qualitative character and the technique used was the focus group. The children's responses make it possible to understand how much their speeches are without prejudice, learned socially. This space of Early Childhood Education reveals itself as a fertile ground for the construction of a more human, autonomous and less sexist formation.

Keywords: Early Childhood Education. Genre. Morality. Human formation

\section{REFERÊNCIAS}

ALVES, Hildinéia. Moralidade e gênero na concepção de educação da educação infantil: uma intervenção que valoriza a oralidade e a criatividade. 2020. 156 p. Dissertação (Mestrado)-Universidade Estadual Paulista. Faculdade de Ciências, Bauru, 2020.

ARANTES, Valéria; ARAUJO, Ulisses F.; SILVA, Marco Antonio Morgado da. Josep Maria Puig: uma vida dedicada à Educação em Valores. Educ. Pesqui., São Paulo, v. 45, e201945002001，2019. Disponível em: http://www.scielo.br/scielo.php?script=sci arttext\&pid=S1517-97022019000100200\&lng=en\&nr $\underline{\mathrm{m}=\mathrm{iso}}$. Acesso em 27 Abr. 2020.

ARROYO, MIGUEL G. Artigo - Paulo Freire: outro paradigma pedagógico ? Educ. rev. , Belo Horizonte, v. 35, e214631, 2019. Disponível em https://www.scielo.br/scielo.php?pid=S0102$\underline{46982019000100202 \& \text { script }=\text { sci arttext. }}$ acesso em 10 de junho de 2020.

BARREIRO, Alice. O desenvolvimento do juízo moral. In: CARRETEIRO, Mário e CASTORINA, José A. (org.). Desenvolvimento cognitivo e educação: processos do conhecimento e conteúdos específicos. Porto Alegre: Penso, v.2, 2014, p. 182-202.

BRASIL. Constituição. Constituição da República Federativa do Brasil. Brasília, DF, Senado, 1998.

BRASIL. Lei $n^{\circ} 8.069$, de 13/07/1990. Dispõe sobre o Estatuto da criança e do adolescente (ECA). BRASIL. Lei n ${ }^{\circ} 9.394$ de 20/12/1996. Lei de diretrizes e bases da Educação Nacional (LDBEN). BRASIL. Lei ${ }^{\circ} 12.796$, de 04/04/2013. Altera a Lei ${ }^{\circ} 9.394$, de 20 de dezembro de 1996, que estabelece as diretrizes e bases da educação nacional, para dispor sobre a formação dos profissionais da educação e dar outras providências.

BRASIL. Ministério da Saúde. Secretaria de Políticas de Saúde. Comitê de Primeira Infância. Políticas intersetoriais em favor da infância: guia referencial para gestores municipais. Brasilia: Ministério da Saúde, 2002.

CAMBI, Franco. História da pedagogia. São Paulo: Editora UNESP, 1999.

CARDONA, Maria J. et all. Guião de educação gênero e cidadania: pré-escolar. Lisboa: Editorial do Ministério da Educação e Ciência, 2015. In: https://www.cig.gov.pt/wp-content/ uploads/2015/10/398 15 Guiao Pre escolar.pdf. Acessado em 12 de junho de 2020.

CURY, Carlos Roberto Jamil. A educação básica como direito. Cad. Pesqui. [online]. 2008, vol.38, 
n.134, pp.293-303. ISSN 1980-5314. https://doi.org/10.1590/S0100-15742008000200002. Acesso em 29 Maio. 2020.

FREIRE, Paulo. Pedagogia da autonomia: saberes necessários a prática educativa. $25^{a}$ ed. São Paulo: Paz e Terra, 1996.

GATTI, Bernadete Angelina. Grupo focal na pesquisa em ciências sociais e humanas. Brasília: Líber Livro, 2005.

GÓMEZ, Angel I. P. As funções sociais da escola: da reprodução à reconstrução crítica do conhecimento e da experiência. In: SACRISTÁN, José G. e GÓMEZ, Angel I. Compreender e transformar o ensino, $4^{a}$ ed. Porto Alegre: 2007, p. 13-26.

IMBERNÓN, Francisco (org.). A educação no século XXI. Porto Alegre: Artmed, 2000

LARAIA, Roque de Barros. Cultura: um conceito antropológico. 17aaed. Rio de Janeiro: Jorge Zahar, 2004.

LA TAILLE, Ives. O lugar da interação social na concepção de Jean Piaget. In: LA TAILLE, Ives , DANTAS, Heloisa e OLIVEIRA, Marta K.. Piaget, Vygotsky e Wallon. Teorias Genéticas em Discussão. São Paulo: Summus, 1992, p.11-21.

. O despertar do senso moral. Revista Pátio de Educação Infantil. Ano III, n.7, MAI/JUN de

2005.

LOURO, Guacira Lopes. Gênero, sexualidade e educação: uma perspectiva pós-estruturalista. Petrópolis: Vozes, 1997

PASCOAL, Jaqueline D. e MACHADO, Maria C. A história da educação infantil no Brasil: avanços, retrocessos e desafios dessa modalidade educacional. Revista HISTEDBR On-line, Campinas, n.33, p.78-95, mar. 2009. In: http://www.histedbr.fe.unicamp.br/revista/edicoes/33/art05 33.pdf. Acesso em 29 Maio. 2020.

PELÚCIO, Larissa. Concepções e análise do material didático na perspectiva da diversidade. In: MORAES, Mara Sueli Simão; REBECHI JUNIOR, Arlindo (Orgs). O uso de linguagens no ensino de temas da diversidade. São Paulo: Cultura Acadêmica, 2015, p. 12-41 (Coleção Produção de Material Didático para Diversidade).

PRADO, Patrícia Dias; ANSELMO, Viviane Soares. Masculinidades, feminilidades e dimensão brincalhona: reflexões sobre gênero e docência na Educação infantil. Pro-Posições, Campinas, v. 30, e20170137, 2019. Available from <http://www.scielo.br/scielo.php?script=sci_arttext\&pid=S010373072019000100555\&lng=en\&nrm=iso $>$. access on 14 June 2020. Epub Dec 02, 2019. https://doi. org/10.1590/1980-6248-2017-0137. Acesso em 14 JUN. 2020.

PIAGET, Jean. O juízo moral na criança. São Paulo: Summus, 1994.

SACRITÁN, José G. A educação que temos, a educação que queremos. In: IMBERNÓN, Francisco (org.). A educação no século XXI. Porto Alegre: Artmed, 2000, p. 37-63.

STRECK, Danilo R. et al. Educação Popular e Docência. São Paulo: Cortez Editora, 2014. v. 1.

SCOTT, Joan. Gênero: uma categoria útil de análise histórica. Educação \& Realidade. Vol.20(2). Jul/ Dez. 1995 , p. $71-99$. 